\title{
Effect of intracanal diode laser application and low-level laser therapy on CGRP change
}

\author{
Hakan ARSLAN(a) \\ Serhat KÖSEOĞLU(b) \\ Ezgi DOĞANAY YILDIZ(c) \\ Taner ARABACI(d) \\ Levent SAVRAN(e) \\ Dursun Anıl YILDIZ(d) \\ Gözde VEYISOĞLU(f) \\ (a)Atatürk University, Faculty of Dentistry, \\ Department of Endodontics, Erzurum, Turkey. \\ (b)Sağlık Bilimleri University, Faculty of \\ Dentistry, Department of Periodontology, \\ Istanbul, Turkey. \\ (c) Kırıkkale University, Faculty of Dentistry, \\ Department of Endodontics, Kırıkkale, Turkey. \\ (d)Atatürk University, Faculty of Dentistry, \\ Department of Periodontology, \\ Erzurum, Turkey. \\ (e) Izmir Katip Celebi University, Faculty of \\ Dentistry, Department of Periodontology, \\ Izmir, Turkey. \\ (f)Başkent University, Faculty of Dentistry, \\ Department of Periodontology, Ankara, Turkey.
}

Declaration of Interests: The authors certify that they have no commercial or associative interest that represents a conflict of interest in connection with the manuscript.

Corresponding Author:

Ezgi Doğanay Yildiz

E-mail:dtezgidoganay@gmail.com

https://doi.org/10.1590/1807-3107bor-2018.vol32.0125

Submitted: May 30, 2018

Accepted for publication: October 10, 2018

Last revision: November 05, 2018

\begin{abstract}
The aim of this study was to investigate the effect of a placebo, intracanal diode laser application, and low-level laser therapy (LLLT) on the change of the total amount of calcitonin gene-related peptide (CGRP) in the gingival crevicular fluid (GCF) (split-mouth study design). GCF sampling was performed on a contralateral tooth and experimental tooth (root canal-treated tooth) of thirty-nine patients. The patients were divided into three groups $(\mathrm{n}=13)$, as follows: placebo (mock laser application), intracanal laser application, and LLLT. GCF sampling was repeated at the same sites (experimental and control teeth) one week after root canal treatment. The data were analyzed using the Pearson's correlation analysis and the independent-samples t-tests $(\mathrm{p}=0.05)$. In the placebo group, the total CGRP level changes in the GCF before and after treatment was significantly higher for experimental teeth than for control teeth $(\mathrm{p}<0.05)$. However, there was no significant difference between experimental and control teeth in the intracanal laser application and LLLT groups $(p>0.05)$. Intracanal laser application and low-level laser therapy have immunomodulation effects linked to the modulation of the total amount of CGRP in the GCF.
\end{abstract}

Keywords: Calcitonin Gene-Related Peptide; Lasers; Gingival Crevicular Fluid; Low-Level Laser Therapy.

\section{Introduction}

Root canal treatment usually results in varying levels of post-operative spontaneous pain or pain on percussion. ${ }^{1,2,3}$ During root canal treatment, the extrusion of various irritants such as pulp tissue, dentinal debris, and bacteria from the root canal to periapical tissues can initiate inflammation in the periodontal ligament, which, when accompanied by clinical pain, is named 'symptomatic apical periodontitis'. However, the degree of the inflammation does not correlate with the severity of the pain. ${ }^{4}$

In 1901, Bayliss ${ }^{5}$ first demonstrated vasodilation after the stimulation of neurons. Since then, the release of pro-inflammatory neuropeptides has been demonstrated after the stimulation of the primary afferent neurons or the activation of polymodal nociceptive receptors. These pro-inflammatory neuropeptides interact with certain cells and initiate a cascade of inflammation resulting in vasodilatation, plasma-protein 
extravasation, and hypersensitivity, a phenomenon referred to as 'neurogenic inflammation'.

Pro-inflammatory neuropeptides are small proteinaceous substances produced and released by neurons through the regulated secretary route that act on neural substrates. ${ }^{7}$ Calcitonin gene-related peptide (CGRP), one of the pro-inflammatory neuropeptides, has roles in inflammation and immunomodulation and is associated with specific immune cells, including $\mathrm{T}$ cells, mast cells, and dendritic cells. CGRP is the main neuropeptide activating neurogenic vasodilation of blood vessels. ${ }^{8,9}$ CGRP has two isoforms; $\alpha$-CGRP, mainly present in sensory neurons, and $\beta$-CGRP, preferentially expressed in enteric myenteric and submucosal intrinsic neurons. ${ }^{6} \mathrm{CGRP}$-containing nerve fibers are widely distributed in the body including in peripheral tissues (pulp and periodontium), trigeminal ganglion, and trigeminal nucleus., ${ }^{9,11,1,12}$

Lasers can be used intracanal or intraorally (low-level laser therapy-LLLT). Intracanal laser application has been extensively studied and found to be effective in removing the smear layer in the apical thirds of root canals ${ }^{13}$ as well as in decreasing microbial load in dentinal tubules. ${ }^{14,15}$ In addition to the bacterial reduction effect of intracanal laser application, Silva et al. ${ }^{16}$ showed that it results in less permeability of root canal dentin, while MonteroMiralles et al. ${ }^{17}$ reported that it enhances the sealer adaptation to the dentinal walls. Moreover, intracanal laser application has an immunomodulation effect suggesting a sedative effect on peripheral C-fibers in the periodontal ligament. ${ }^{4}$

LLLT increases endogenous endorphins ( $\beta$-endorphin) and decreases the activity of $C$-fibers and bradykinin, and thus creates an analgesic effect. ${ }^{18,19}$ LLLT application also increases phagocytic activity and the number and diameter of lymphatic vessels, decreases the permeability of blood vessels, reducing edema. LLLT also reduces post-operative symptoms due to these effects. ${ }^{20}$ This treatment is nowadays called "photobiomodulation", but it also has many different names in the scientific literature; LLLT has been the most commonly used term.

To the best of our knowledge, there is no information about the effect of diode lasers on the levels of CGRP. Thus, the purpose of this study was to investigate the effect of a placebo, intracanal diode laser application, and low-level laser therapy on the total amount of CGRP in gingival crevicular fluid pre- and postoperatively compared to that of a healthy contralateral tooth (split-mouth study design). The null hypothesis was that there is no significant difference between the test and control groups.

\section{Methodology}

\section{Sample size}

A split-mouth study design was planned, the power analysis being conducted according to an independentsample t-test. The effect size was obtained from the study by Caviedes-Bucheli et al. ${ }^{11}$ and a sample size of 10 patients for each group was calculated to be sufficient (100\% power, effect size 7.5). Finally, the sample size was determined as 13 for each group to allow for any loss of patients during follow-up. All accepted patients were randomly assigned to three treatment groups as follows: placebo group, intracanal laser application, and LLLT.

\section{Patient selection}

The protocol was approved by the Research Ethics Committee, with each patient providing written and verbal informed consent to participate in the study. Patients referred to the Department of Endodontics of the Faculty of Dentistry of Ataturk University, Erzurum, Turkey for management and treatment of teeth with symptomatic apical periodontitis were evaluated as possible candidates for this study. Patients over 18 years of age with a mandibular molar tooth with symptomatic apical periodontitis were considered. Exclusion criteria were systematic diseases, known allergic reactions, had taken medication within the last three days, had swelling or sinus tract, severe periodontal disease, or if the tooth had previously been treated with root canal therapy, had periodontal probing depths of more than $3 \mathrm{~mm}$, or periapical radiolucency. Patients were excluded from the study if teeth had curved roots, excessively long or short root length, or problems in determining working length, broken files, over-instrumentation, over-filling 
or incomplete filling, or if the patient had any complications during treatment.

\section{Clinical measurements}

Each patient's pain level (pre-operative spontaneous pain and pain on percussion) was recorded before the initiation of each treatment procedure using the visual analog scale (VAS) score (0-100 scale: 0 , no pain, to 100, extremely severe pain).

For the percussion test, the cusp tips of each tooth were percussed three times using the shaft of a periodontal probe. First, a normal asymptomatic tooth was tested so the patient could experience the normal tapping sensation of the percussion test and to rule out any false positive response. Then, the experimental tooth and its adjacent tooth were tested in a randomized order, and the pain of the experimental tooth was recorded using VAS scores.

\section{Gingival crevicular fluid (GCF) sampling}

A contralateral tooth was selected as control tooth. The sites selected (experimental and control teeth) for GCF sampling were isolated using cotton wool rolls and a saliva ejector. Supragingival plaque was carefully removed using a curette. The teeth to be sampled were dried with warm air for $10 \mathrm{~s}$. A Periopaper strip (Oraflow, Smithtown, NY, USA) was placed within the mesial interproximal gingival crevice of each tooth until slight resistance was encountered. The Periopaper strips were removed from the gingival sulcus after $30 \mathrm{~s}$. Samples contaminated by blood or saliva were rejected. For both the experimental and control tooth, samples were collected using two Periopaper strips. The volume of GCF was determined using a Periotron 8000 (Oraflow). The Periopaper strip was placed in an Eppendorf tube containing $500 \mu \mathrm{L}$ of ice-cold $0.01 \mathrm{M}$ sodium phosphate buffer, $\mathrm{pH} 7.2$, and $0.15 \mathrm{M}$ sodium chloride. The readings were converted to an actual volume by referring to the standard curve. All GCF samples were kept at $-80^{\circ} \mathrm{C}$ until laboratory analysis. All pre-operative GCF samples were collected before local anesthesia was administered.

For post-operative sample collection, GCF sampling was repeated from the same sites (experimental and control teeth) one week after the root canal treatment.

\section{Root canal treatment}

Following patient signing of the informed consent forms, mandibular block anesthesia was performed. After access cavity preparation, the tooth was isolated with a rubber dam. For working length determination, an electronic apex locator (Propex Pixi; Dentsply Maillefer, Ballaigues, Switzerland) was used. For each patient, new Reciproc instruments were used according to the manufacturer's instructions. A total of $2 \mathrm{~mL} \mathrm{1 \%} \mathrm{NaOCl}$ was used between in-and-out pecking motions, and $5 \mathrm{~mL}$ of $1 \% \mathrm{NaOCl}$ for $1 \mathrm{~min}$, with $5 \mathrm{~mL}$ of $5 \%$ EDTA for $1 \mathrm{~min}$ for the final rinse. Then, the root canals were dried with paper points and filled using matched single cones and 2Seal sealer (VDW, Munich, Germany). A flowable composite resin and a nanohybrid composite resin were used for tooth restoration.

\section{Experimental groups}

The patients were divided into three groups ( $\mathrm{n}=13$ ), as follows:

Placebo: The diode laser tip was placed at a distance of approximately $10 \mathrm{~mm}$ from the tissue around the apex of the root, but it was not activated.

Intracanal laser application: After the final irrigation protocol was performed and the root canals dried, an intracanal laser application was performed for each root canal using a 200 micron optical tip at $2 \mathrm{~W}$. The application began at $1 \mathrm{~mm}$ from the working length and an up-and-down motion then applied up to $1 \mathrm{~mm}$ from the working length under continuous irrigation with distilled water. The total application time was $60 \mathrm{~s}$ for each tooth.

Low-level laser therapy (LLLT): Subsequently to completion of the root canal treatment, the laser application tip with a 200-micron optical fiber was placed at a distance of approximately $10 \mathrm{~mm}$ from the tissue around the apex of the root and activated at $0.5 \mathrm{~W}$ and $10 \mathrm{~Hz}$. The total application time was $60 \mathrm{~s}$ (30 s for the distal root and $30 \mathrm{~s}$ for the mesial root) for each tooth. Energy density was $2.86 \mathrm{~J} / \mathrm{cm}^{2}$ and cumulative dose was $171.6 \mathrm{~J} / \mathrm{cm}^{2}$. 


\section{Laser device properties}

The laser device used in this study was a 970 \pm 15 -nm diode laser with a $10-\mathrm{W}$ source power (SIROLaser Xtend; Sirona Dental Systems GmbH, Bensheim, Germany).

Endodontic treatment was performed by E.D.Y, the laser treatments were administered by H.A., and the GCF samples were taken by another researcher (D.A.Y).

\section{Measurement of CGRP in GCF}

The CGRP level in the GCF was measured by enzyme linked immune assay (ELISA) kit (Cayman, Ann Arbor, MI). The instructions for assay procedures were applied as recommended by the manufacturer. All samples and reagents were thawed until they reached room temperature. Pre-coated microtiter plates were rinsed five times with wash buffer (300 $\mu \mathrm{L} /$ well) prior to the distribution of reagents and samples. $100 \mu \mathrm{L}$ of each sample, standard and reagents, were pipetted to the wells and incubated for 18 hours at $4^{\circ} \mathrm{C}$. After washing the 96 wells six times with wash buffer, $200 \mu \mathrm{L}$ of Ellman's reagent was dispensed into each well and incubated in the dark at room temperature for 45 minutes using an orbital shaker. The plate was read at $410 \mathrm{~nm}$ by microplate reader (Multiskan GO Microplate Spectrophotometer; Thermofisher, Waltham, MA, USA) and concentrations of the samples were calculated with the software provided by the reader's manufacturer, using a linear curve fit. The diluted CGRP absorbance values (picograms per microliter) in the GCF were multiplied by the dilution agent volume (500 $\mu \mathrm{L}$ PBS), and then this value was divided by the number of strips (two) to determine the total amount of CGRP collected in 30 seconds (picograms per 30 seconds). The data for the total CGRP levels in the GCF samples were obtained by S.K.

\section{Statistical analysis}

The Pearson's correlation analysis was used to determine correlations among VAS, total CGRP levels, and demographic data. The differences between experimental and control teeth in terms of total amount of CGRP were analyzed using the independent-sample t-test $(p=0.05)$.

\section{Results}

Seventy-eight teeth ( 39 experimental and 39 control) from 39 patients (21 men and 18 women) were enrolled in this study. No patient was lost during follow-up. The demographic features and pain characteristics are presented in Table. There was no statistically significant difference between groups in terms of demographic features and pre-operative pain levels $(\mathrm{p}>0.05)$.

The total CGRP level change in the GCF for the placebo before and after the treatment were as follows: experimental, $0.69 \pm 0.79 \mathrm{pg} / 30 \mathrm{sec}$, and control, $-0.56 \pm 1.17 \mathrm{pg} / 30 \mathrm{sec}$ (Figure 1). The total CGRP change in the GCF for the intracanal laser application before and after the treatment were as follows: experimental, $0.06 \pm 0.37 \mathrm{pg} / 30 \mathrm{sec}$, and

Table. Demographic data and pre- and post-operative (seven days after the root canal treatment) VAS scores according to groups.

\begin{tabular}{lcccc}
\hline Variable & Control group & Intracanal laser application & LLLT & p-value \\
\hline Age & $28.1 \pm 8.9$ & $24 \pm 3.9$ & 27.9 .4 & $<0.05$ \\
Sex & & & & \\
$\quad$ Male & 7 & 6 & 6 & $<0.05$ \\
$\quad$ Female & 6 & 7 & $91.3 \pm 7.1$ & $<0.05$ \\
Pre-operative pain & $89.8 \pm 11.9$ & $85.9 \pm 11.1$ & $82.9 \pm 9.6$ & $<0.05$ \\
Pre-operative percussion & $77.3 \pm 10.9$ & $78.7 \pm 11.3$ & $0 \pm 0$ & $<0.05$ \\
Post-operative pain & $2.5 \pm 4.3$ & $5 \pm 13.7$ & $0.1 \pm 0.5$ & $>0.05$ \\
Post-operative percussion & $8.6 \pm 10.9$ & $5.5 \pm 7.1$ & & \\
\hline
\end{tabular}

LLLT: low-level laser therapy. 


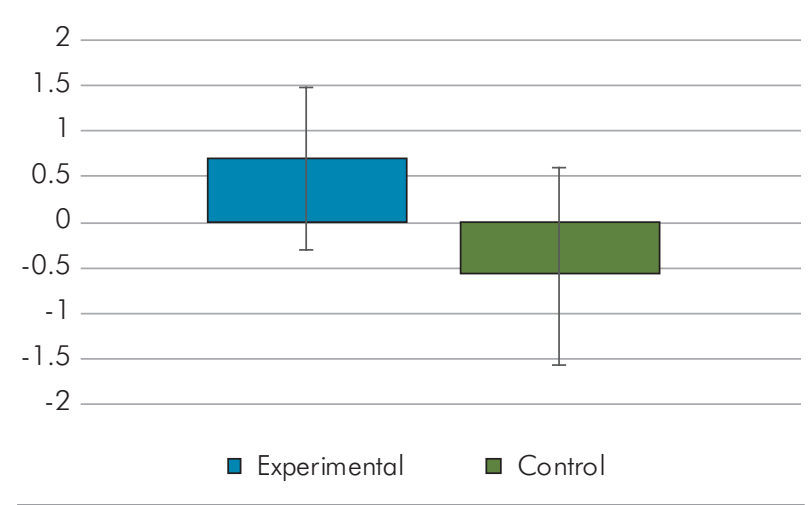

Figure 1. CGRP results for experimental and control teeth in placebo group; the total CGRP level change in the GCF before and after treatment was significantly higher for experimental teeth than control teeth $(p<0.05)$.

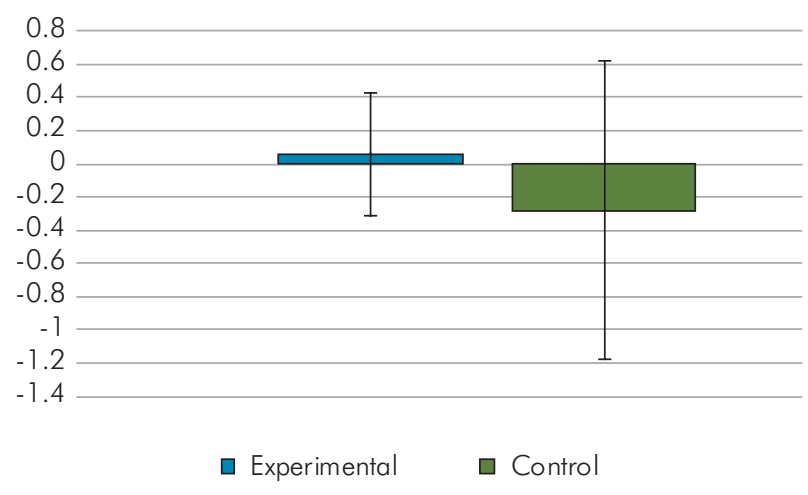

Figure 2. CGRP results for experimental and control teeth in intracanal laser application group; there was no significant difference between experimental and control teeth in the intracanal laser application group in terms of the total CGRP level change in the GCF before and after treatment ( $p>0.05)$.

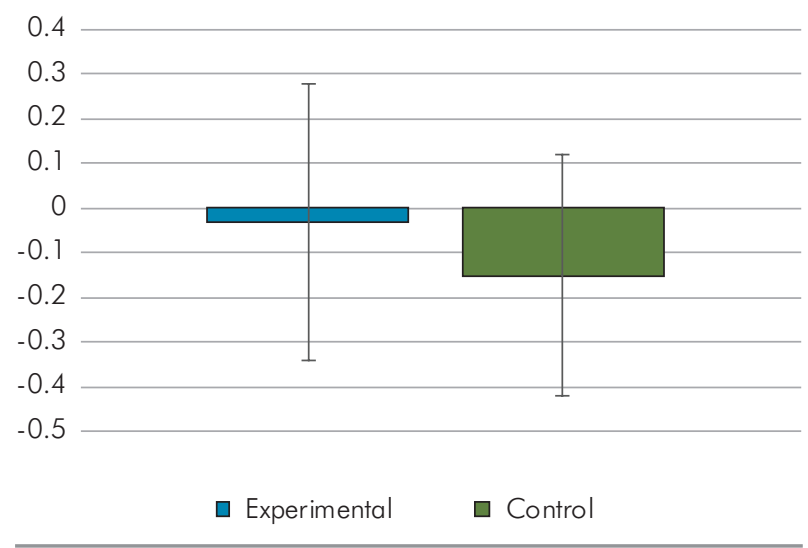

Figure 3. CGRP results for experimental and control teeth in the LLLT group; there was no significant difference between the experimental and control teeth in the LLLT group in terms of the total CGRP level change in the GCF before and after treatment $(p>0.05)$. control, $-0.28 \pm 0.90 \mathrm{pg} / 30 \mathrm{sec}$ (Figure 2). The total CGRP level change in the GCF for LLLT before and after the treatment were as follows: experimental, $-0.03 \pm 0.31 \mathrm{pg} / 30 \mathrm{sec}$, and control, $-0.15 \pm 0.27 \mathrm{pg} / 30 \mathrm{sec}$ (Figure 3).

In the placebo group, the CGRP change in the GCF before and after treatment was significantly higher for experimental teeth than that for control teeth $(\mathrm{p}<0.05)$. However, there was no significant difference between the experimental and control teeth for the intracanal laser application and LLLT groups ( $p>0.05)$.

The Pearson's correlation analysis revealed that post-operative VAS scores of pain on percussion were positively correlated with the pre-operative $(p<0.05$; $r=0.51)$ and post-operative total amount of CGRP in GCF $(\mathrm{p}<0.05 ; \mathrm{r}=0.43)$.

\section{Discussion}

CGRP is an important neuropeptide in inflammation and immunomodulation. Its main role is the vasodilation of blood vessels. ${ }^{8,9}$ Recently, the neodymium-doped yttrium aluminum garnet laser has been shown to be useful in immunomodulation by affecting neuropeptides. ${ }^{4}$ However, there is no available information about the effect of LLLT and intracanal diode laser applications on the total amount of CGRP. Thus, the purpose of this study was to investigate the effect of a placebo, intracanal diode laser application, and LLLT on the total CGRP level in GCF in teeth in need of root canal treatment pre- and post-operatively compared to that of healthy contralateral teeth (split-mouth study design).

The immunomodulation effect of lasers is controversial. In a recent study, Silva et al..$^{21}$ evaluated the effect of LLLT on the severity of oral mucositis and inflammatory mediator (TNF- $\alpha$, IL-6, IL-1 $\beta$, IL-10, TGF- $\beta$, metalloproteinases, and growth factors) levels in saliva and blood of hematopoietic stem cell transplantation patients. The authors found that LLLT was clinically effective, and that the LLLT mechanism does not seem to be completely linked to the modulation of pro- or anti-inflammatory cytokines, growth factors, or matrix metalloproteinases. However, Moreira et al., ${ }^{22}$ analyzing the effect of diode laser 
therapy on local and systemic immunomodulation following cryogenic brain injury, found that diode laser therapy can affect the TNF- $\alpha$, IL-1 $\beta$, and IL- 6 levels in the brain and in circulation during the first 24 hours following cryogenic brain injury. Similarly, Hsieh et al. ${ }^{23}$ found that LLLT can significantly modulate substance $\mathrm{P}$ levels in the dorsal root ganglion.

In the present study, a split-mouth design was used and no significant difference was observed between experimental and control teeth in intracanal laser application and LLLT groups, although there were significant differences for the placebo group. Thus, the null hypothesis was partially rejected. The results of the present study suggest that intracanal laser application and LLLT have an immunomodulation effect. In the laser treatment groups, the change in CGRP levels for experimental teeth was closer to that of healthy teeth than for the placebo group. This finding is in consistent with the results of the study by Yoo et al. ${ }^{4}$ mentioned above, that the ability of the Nd:YAG laser in immunomodulation comes through the effect on neuropeptides. The differences among the studies are due to the different areas in which the laser was applied, laser parameters, and study designs.

Although root canal treatment aims to remove the source of inflammation, inflammation originating from pulpal tissue can extend to periapical tissue and thus induce inflammation. Although LLLT differs from intracanal laser application in terms of methods and application location, the results for CGRP levels were similar for LLLT and intracanal laser application. Recently, it has been shown that intracanal laser application significantly reduced CGRP levels in root canal exudate samples. ${ }^{4}$ Similarly, according to the results of this split-mouth design study, it has been found that the intracanal diode laser application had an immunomodulation effect linked to the modulation of the CGRP levels in the GCF. This may result from the sedative effect of the intracanal laser application on peripheral C-fibers in the periodontal ligament. ${ }^{4}$ LLLT also has positive effects on inflammation and the immune system by increasing endogenous endorphins ( $\beta$-endorphin) and inducing phagocytic activity. In addition, it increases the number and diameter of lymphatic vessels while reducing the permeability of blood vessels, and thus reduces edema and the activity of C-fibres and bradykinin. ${ }^{18,19,20,24}$

Cytokine levels vary by individual, for which reason a split-mouth design study was planned, enabling the pre-operative and post-operative CGRP levels of an individual's experimental tooth to be compared with the contralateral healthy tooth.

CGRP is a pro-inflammatory mediator that causes neurogenic inflammation, during which pain sensitivity increases and pain threshold decreases. Another finding of the present study was that the post-operative VAS scores of pain on percussion were positively correlated with pre- and post-operative GCF total CGRP levels. This finding is consistent with the results of the study by Yoo et al. ${ }^{4}$ who found a positive correlation between the VAS scores of pain on percussion and CGRP levels.

Samples from the root canal, ${ }^{23} \mathrm{GCF}_{,}{ }^{25}$ or periodontal ligament of extracted teeth ${ }^{11,12}$ have been used to identify markers of inflammation. Sample collection from the root canal or periodontal ligament of an extracted tooth is not possible in a split-mouth study. It has been found that there is a relationship between the changes in the levels of neuropeptides in GCF and endodontic disease. ${ }^{25}$ Because a split-mouth design was used and the pre- and post-treatment levels of CGRP compared, GCF sampling was the most appropriate method for this study. The sample collection method employed here is a non-invasive technique, not requiring tooth extraction or excision of any tissue.

GCF has been used in studies related to periodontal and endodontic diseases to determine cytokine levels. ${ }^{26,27}$ Among these studies, total amounts of cytokines and the GCF concentration of cytokines have been used for analyses. ${ }^{26,27,28,29}$ However, it has been reported that the GCF cytokines concentration can be affected by the GCF volume and thus lead to erroneous results. ${ }^{28,29}$ When all samples are collected with a standard sampling time in GCF is used, the total amount of cytokines can be a better indicator than the GCF concentration of cytokines. ${ }^{29}$ Thus, the total amount of CGRP was analyzed for each specimen, with the sampling time in GCF being conducted in a standardized manner. Therefore, in our study, a standardized Periopaper strip was 
inserted into the gingival sulcus for 30 seconds in all sample collections.

Because the LLLT application is more practical than the intracanal laser application, the placebo group mimicked the LLLT laser in the present study.

\section{Conclusion}

Under the conditions of this study, it is possible to conclude that the intracanal laser application and low-level laser therapy have immunomodulation effects linked to the modulation of the total amount of CGRP in the GCF. Further studies are needed to explain the mechanism of this observed effect of diode laser.

\section{Acknowledgment}

The clinical trial registration number is TCTR20161223001 and name of the trial registry is Thai Clinical Trials Registry.

\section{References}

1. Arslan H, Seckin F, Kurklu D, Karatas E, Yanikoglu N, Capar ID. The effect of various occlusal reduction levels on postoperative pain in teeth with symptomatic apical periodontitis using computerized analysis: a prospective, randomized, doubleblind study. Clin Oral Investig. 2017 Apr;21(3):857-63. https://doi.org/10.1007/s00784-016-1835-y

2. Middha M, Sangwan P, Tewari S, Duhan J. Effect of continuous ultrasonic irrigation on postoperative pain in mandibular molars with non-vital pulps: a randomized clinical trial. Int Endod J. 2017 Jun;50(6):522-30. https://doi.org/10.1111/iej.12666

3. Shokraneh A, Ajami M, Farhadi N, Hosseini M, Rohani B. Postoperative endodontic pain of three different instrumentation techniques in asymptomatic necrotic mandibular molars with periapical lesion: a prospective, randomized, doubleblind clinical trial. Clin Oral Investig. 2017 Jan;21(1):413-8. https://doi.org/10.1007/s00784-016-1807-2

4. Yoo YJ, Shon WJ, Baek SH, Kang MK, Kim HC, Lee W. Effect of 1440-nanometer neodymium:yttrium-aluminumgarnet laser irradiation on pain and neuropeptide reduction: a randomized prospective clinical trial. J Endod. 2014 Jan;40(1):28-32. https://doi.org/10.1016/i.joen.2013.07.011

5. Bayliss WM. On the origin from the spinal cord of the vaso-dilator fibres of the hind-limb, and on the nature of these fibres. J Physiol. 1901 Feb;26(3-4):173-209. https://doi.org/10.1113/iphysiol.1901.sp000831

6. Malhotra R. Understanding migraine: potential role of neurogenic inflammation. Ann Indian Acad Neurol. 2016 AprJun;19(2):175-82. https://doi.org/10.4103/0972-2327.182302

7. Burbach JP. What are neuropeptides? In: Merighi A, editor. Neuropeptides: methods and protocols. Totowa: Humana Press; 2011. p. 1-36.

8. Olivar T, Razzaque Z, Nwagwu M, Longmore J. Neurogenic vasodilation in rabbit basilar isolated artery: involvement of calcitonin-gene related peptide. Eur J Pharmacol. 2000 Apr;395(1):61-8. https://doi.org/10.1016/S0014-2999(00)00153-9

9. Assas BM, Pennock JI, Miyan JA. Calcitonin generelated peptide is a key neurotransmitter in the neuro-immune axis. Front Neurosci. 2014 Feb;8:23. https://doi.org/10.3389/fnins.2014.00023

10. Burns LE, Ramsey AA, Emrick JJ, Janal MN, Gibbs JL. Variability in Capsaicin-stimulated Calcitonin Gene-related Peptide Release from Human Dental Pulp. J Endod. 2016 Apr;42(4):542-6. https://doi.org/10.1016/i.joen.2015.12.010

11. Caviedes-Bucheli J, Azuero-Holguin MM, GutierrezSanchez L, Higuerey-Bermudez F, Pereira-Nava V, Lombana $\mathrm{N}$ et al. The effect of three different rotary instrumentation systems on substance $P$ and calcitonin gene-related peptide expression in human periodontal ligament. J Endod. 2010 Dec;36(12):1938-42. https://doi.org/10.1016/i.joen.2010.08.043

12. Caviedes-Bucheli J, Moreno JO, Carreño CP, Delgado R, Garcia DJ, Solano J et al. The effect of single-file reciprocating systems on Substance $P$ and Calcitonin gene-related peptide expression in human periodontal ligament. Int Endod J. 2013 May;46(5):419-26. https://doi.org/10.1111/iej.12005

13. Arslan H, Ayrancı LB, Karatas E, Topçuoğlu HS, Yavuz MS, Kesim B. Effect of agitation of EDTA with 808-nanometer diode laser on removal of smear layer. J Endod. 2013 Dec;39(12):1589-92. https://doi.org/10.1016/i.joen.2013.07.016

14. Souza EB, Cai S, Simionato MR, Lage-Marques JL. High-power diode laser in the disinfection in depth of the root canal dentin. Oral Surg Oral Med Oral Pathol Oral Radiol Endod. 2008 Jul;106(1):e68-72. https://doi.org/10.1016/i.tripleo.2008.02.032

15. Kreisler M, Kohnen W, Beck M, Al Haj H, Christoffers AB, Götz $\mathrm{H}$ et al. Efficacy of $\mathrm{NaOCl} / \mathrm{H} 2 \mathrm{O} 2$ irrigation and GaAlAs laser in decontamination of root canals in vitro. Lasers Surg Med. 2003;32(3):189-96. https://doi.org/10.1002/Ism.10148 
Effect of intracanal diode laser application and low-level laser therapy on CGRP change

16. Silva AC, Guglielmi C, Meneguzzo DT, Aranha AC, Bombana AC, Eduardo CP. Analysis of permeability and morphology of root canal dentin after Er,Cr:YSGG laser irradiation. Photomed Laser Surg. 2010 Feb;28(1):103-8. https://doi.org/10.1089/pho.2008.2417

17. Montero-Miralles P, Castillo-Oyagüe R, Sáez de la Fuente I, Lynch CD, Castillo-Dalí G, Torres-Lagares D. Effect of the $\mathrm{Nd}: Y A G$ laser on sealer penetration into root canal surfaces: a confocal microscope analysis. J Dent. 2014 Jun;42(6):753-9. https://doi.org/10.1016/j.jdent.2014.03.017

18. Sun G, Tunér J. Low-level laser therapy in dentistry [viii.]. Dent Clin North Am. 2004 Oct;48(4):1061-76. https://doi.org/10.1016/i.cden.2004.05.004

19. Hagiwara S, Iwasaka H, Okuda K, Noguchi T. GaAlAs (830 nm) low-level laser enhances peripheral endogenous opioid analgesia in rats. Lasers Surg Med. 2007 Dec;39(10):797-802. https://doi.org/10.1002/Ism.20583

20. Boschi ES, Leite CE, Saciura VC, Caberlon E, Lunardelli A, Bitencourt $S$ et al. Anti-Inflammatory effects of low-level laser therapy $(660 \mathrm{~nm})$ in the early phase in carrageenan-induced pleurisy in rat. Lasers Surg Med. 2008 Sep;40(7):500-8. https://doi.org/10.1002/Ism.20658

21. Silva GB, Sacono NT, Othon-Leite AF, Mendonça EF, Arantes AM, Bariani $C$ et al. Effect of low-level laser therapy on inflammatory mediator release during chemotherapy-induced oral mucositis: a randomized preliminary study. Lasers Med Sci. 2015 Jan;30(1):117-26. https://doi.org/10.1007/s10103-014-1624-2

22. Moreira MS, Velasco IT, Ferreira LS, Ariga SK, Barbeiro DF, Meneguzzo DT et al. Effect of phototherapy with low intensity laser on local and systemic immunomodulation following focal brain damage in rat. J Photochem Photobiol B. 2009 Dec;97(3):145-51. https://doi.org/10.1016/i.jphotobiol.2009.09.002
23. Hsieh YL, Hong CZ, Chou LW, Yang SA, Yang CC. Fluencedependent effects of low-level laser therapy in myofascial trigger spots on modulation of biochemicals associated with pain in a rabbit model. Lasers Med Sci. 2015 Jan;30(1):209-16. https://doi.org/10.1007/s10103-014-1654-9

24. Biordal JM, Johnson MI, Iversen V, Aimbire F, LopesMartins RA. Low-level laser therapy in acute pain: a systematic review of possible mechanisms of action and clinical effects in randomized placebo-controlled trials. Photomed Laser Surg. 2006 Apr;24(2):158-68. https://doi.org/10.1089/pho.2006.24.158

25. Awawdeh LA, Lundy FT, Linden GJ, Shaw C, Kennedy JG, Lamey PJ. Quantitative analysis of substance P, neurokinin $A$ and calcitonin gene-related peptide in gingival crevicular fluid associated with painful human teeth. Eur J Oral Sci. 2002 Jun;110(3):185-91. https://doi.org/10.1034/j.1600-0447.2002.21236.x

26. Karapanou V, Kempuraj D, Theoharides TC. Interleukin-8 is increased in gingival crevicular fluid from patients with acute pulpitis. J Endod. 2008 Feb;34(2):148-51. https://doi.org/10.1016/j.joen.2007.10.022

27. Behfarnia P, Saied-Moallemi Z, Javanmard SH, Naseri R. Serum, saliva, and GCF concentration of RANKL and osteoprotegerin in smokers versus nonsmokers with chronic periodontitis. Adv Biomed Res. 2016 Apr;5(1):80. https://doi.org/10.4103/2277-9175.180992

28. Tsai CC, Ho YP, Chen CC. Levels of interleukin-1 beta and interleukin- 8 in gingival crevicular fluids in adult periodontitis. J Periodontol. 1995 Oct;66(10):852-9. https://doi.org/10.1902/jop.1995.66.10.852

29. Köseoğlu S, Sağlam M, Pekbağrıyanık T, Savran L, Sütçü R. Level of interleukin-35 in Gingival crevicular fluid, saliva, and plasma in periodontal disease and health. J Periodontol. 2015 Aug;86(8):964-71. https://doi.org/10.1902/jop.2015.140666 